\title{
Oral Malodor
}

Vikram Reddy $\mathrm{G}^{1}$, Abhinav $\mathrm{A}^{2}$, J agadish Reddy ${ }^{3}$, Satyanarayana $D^{4}$

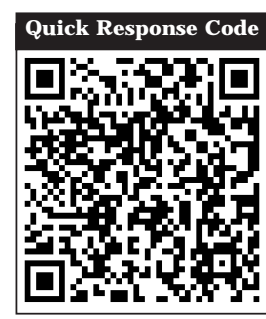

doi: $10.5866 / 2014.621537$

${ }^{1 \& 3}$ Reader

2Post Graduate Student

${ }^{4}$ Professor

Department of periodontics, Kamineni Institute of Dental Sciences, Narketpally, Nalgonda Dist. India

\section{Article Info:}

Received: J anuary 10, 2014

Review Completed: February 8, 2014

Accepted: March 7, 2014

Available Online: J uly, 2014 (www.nacd.in)

(C) NAD, 2014 - All rights reserved

\section{Email for correspondence:}

abhinav_gupta22@yahoo.com

\begin{abstract}
:
Halitosis or bad breath is an oral health condition characterized by unpleasant odours emanating consistently from the oral cavity. The origin of halitosis may be related both to systemic and oral conditions. It often results in psychological alterations and isolation of oneself from being social. This review projects the aetiology, diagnosis and treatment of oral malodor.
\end{abstract}

Key words: halitosis, tongue, periodontits, Aetiology, diagnosis, therapy, therapeutics Cetylpyridinium, zinc.

\section{Introduction}

Halitosis is a general term used to define an unpleasant or offensive odour emanating from the breath regardless of whether the odour originates from oral or non-oral sources.1,2 Other terms used are bad or foul breath, breath malodour, oral malodour, foetor ex-ore, and foetor oris. Halitosis should not beconfused with the generally temporary oral odour caused by intake of certain foods, tobacco, or medications.

Halitosis can be classified into categories of genuine halitosis, pseudo-halitosis, and halitophobia. ${ }^{3} \mathrm{Halitosis}$ may be an important factor in social communication and psychological alterations leading to social and personal isolation.

\section{Aetiology of halitosis:}

Genuine halitosis is multifactorial and may involve both oral and non-oral conditions. However, in approximately $80-90 \%$ of all cases it is caused by oral conditions, defined as oral malodour. ${ }^{1,4}$

\section{Oral malodor}

Oral malodour results from tongue coating, periodontal disease, peri-implant disease, deep carious lesions, exposed necrotic tooth pulps, pericoronitis, mucosal ulcerations, healing (mucosal) wounds, impacted food or debris, imperfect dental restorations, unclean dentures, and factors causing decreased salivary flow rate..$^{5-8}$

Oral malodour arises from microbial degradation of organic substrates, such as glucose, 
mucins, peptides, and proteins present in saliva, crevicular fluid, oral soft tissues, and retained debris. ${ }^{2,9,10}$ Proteins containing the sulphurous amino acids cysteine and methionine, as well as tryptophan and lysine are causative substrates. ${ }^{11,12} \mathrm{Activity}$ of the enzyme b-galactosidase in saliva is an associated cause. ${ }^{13,14}$

Some microbial degradation products are volatile sulphur-containing compounds. Hydrogen sulphide $(\mathrm{H} 2 \mathrm{~S})$, methyl mercaptan $(\mathrm{CH} 3 \mathrm{SH})$, and dimethyl sulphide ((CH3)2S) contribute to the malodour. 2,12 In addition to volatile sulphurcontaining compounds, a contribution has been demonstrated or suggested from short-chain fatty acids (butyrate, propionate, valerate), diamines (cadaverine, putrescine), alcohols, phenyl compounds (indole, skatole, pyridiene), alkines, ketones, and nitrogen-containing compounds (urea, ammonia). ${ }^{15-17}$ Organisms responsible for the hydrolysis of peptides and proteins, and the production of volatilesulphur-containing compounds include proteolytic obligate anaerobes.

Bacteria known to produce volatile sulphurcontaining compounds include Aggregatibacter actinomycetemcomitans (formerly Actinobacillus actinomycetemcomitans), Actinomyces species, Atopobium parvulum, Campylobacter rectus, Desulfovibrio species, Eikenella corrodens, Eubacterium sulci, Fusobacterium species, Peptostreptococcus micros, Porphyromonas endodontalis, Porphyromonas gingivalis, Prevotella species, Solobacterium moorei, Tannerella forsythia (formerly Bacteriodes forsythus or Tannerella forsythensis), Treponema denticola, Veillonella species, Vibrio species, a phylotype of Dialister, a phylotype of the uncultivated phylum, and a phylotype of Streptococcus, and as yet unidentified sulphur-reducing bacteria. ${ }^{15,}$ 18-20

However, no obvious association exists between halitosis and any specific bacterial infection, suggesting that bad breath reflects complex interactions between several oral bacterial species.

\section{Diagnosis}

The clinical assessment of oral malodour is usually subjective and is based on smelling the exhaled air of the mouth and nose and comparing the two (organol eptic assessment). Odour detectable from the mouth but not from the nose is likely to be of oral or pharyngeal origin. Odour from the nose al one is likely to be coming from the nose or sinuses.

Diagnosis of malodor can be diagnosed by the following methods:

\section{Organoleptic measurement}

Organoleptic or hedonic measurement is a simple commonly used measurement method of halitosis by an examiner. A plastic tube is inserted into the patient's mouth, preventing the dilution of mouth air with room air. While the patient is exhaling slowly, the examiner judges the odour at the other end of the tube. A privacy screen with a hole for the straw or thetube can be used to separate the examiner from the patient. Nasal-breath odour can be measured with a tube inserted into one of the nostrils, while the other nostril is closed by a finger. ${ }^{6}$ Various scoring systems can be used for estimating the intensity of the odour. The most widely used scale is ranging from 0 to $5:^{21}$

$$
\begin{aligned}
& 0=\text { no odour, } \\
& 1 \text { = barely noticeable odour, } \\
& 2=\text { slight but clearly noticeable odour, } \\
& 3=\text { moderate odour, } \\
& 4=\text { strong odour, } \\
& 5=\text { extremely foul odour. }
\end{aligned}
$$

However, the reliability and reproducibility of the method are problematic and research projects are carried out attempting to improve the method. ${ }^{22}$ Measurement by a panel of judges is considered to improve the reliability. ${ }^{6,23}$ Agreement among judges may be increased by standardisation of the sense of smell, using an odour solution kit for measuring the olfactory sense and previously assigned scores. For a good agreement between judges, patients must abstain from hygiene practises, smoking, antibiotics, and foods containing garlic, onion, and spices prior to the examination. ${ }^{6}$ F urthermore, the agreement between judges may be increased if they themselves avoid drinking coffee, tea, and juice, smoking, and 
using scented cosmetics before the organoleptic measurements. ${ }^{6}$

Other methods to assess malodor are:

- Gas chromatography

- $\quad$ Sulphide monitoring

- BANA test

- Chemical sensors

- Quantifying b-galactosidase activity

- Salivary incubation test

- Ammonia monitoring

- Ninhydrin method

- Polymerase chain reaction

Therapeutic approach to manage oral halitosis

Successful treatment of halitosis depends on a correct diagnosis and the implementation of a causerelated therapy. ${ }^{3}$ After a positive diagnosis for oral halitosis has been made, the treatment plan is implemented, which comprises elimination of the causative agent and improvement of the oral health status. ${ }^{24}$ Although the multiple possible aetiologies include oral and non-oral causes, the majority of breath malodor cases originate from the oral cavity. Briefly, the treatment of oral malodor can therefore be focused on the reduction of the intraoral bacterial load and/or the conversion of VSC to non-volatile substrates.

Miyazaki et al. (1999) established the recommended examination for halitosis and a classification of halitosis with corresponding treatment needs. Accordingly, different treatment needs (TN) have been described for the various diagnostic categories.

The responsibility for the treatment of physiologic halitosis (TN-1), oral pathologic halitosis (TN-1 and TN-2), and pseudo-halitosis (TN-1 and $\mathrm{TN}-4)$ resides on dental practitioners. However, extra-oral pathologic halitosis (TN-3) and halitophobia (TN - 5) should be managed by a physician or medical specialist and a psychiatrist or psychological specialist.
Table 1 describes the 5 different categories of treatment needs according to diagnosis (Miyazaki et al.22, 1999).

\section{Category DESCRIPTION}

TN-1 Explanation of halitosis and instructions for oral hygiene (support and reinforcement of a patient's own self-care for further improvement of his/her oral hygiene).

TN-2 Oral prophylaxis, professional cleaning and treatment of oral diseases, especially periodontal diseases.

TN-3 Referral to a physician or medical specialist.

TN-4 Explanation of examination data, further professional instruction, education and reassurance.

TN-5 Referral to a clinical psychologist, psychiatrist or other psychological specialist.

The management of halitosis starts by taking a detailed history of the condition, duration, severity, and impact on the patient's everyday life. Special tests are performed to detect the foul-smelling VSCs along with the associated bacteria. Since malodor originating from the mouth is due to the metabolic degradation of available proteinaceous substrates to mal odorous gases by certain oral mi croorganisms, oral malodor can be ameliorated through:

(1) Reduction of bacterial load,

(2) Reduction of nutrient availability,

(3) Conversion of VSC to non-volatiles and

(4) Masking the malodor . 1, 3, 25

\section{Treatment of malodor}

\section{Mechanical approach}

Several studies have implicated the dorsum of the tongue as the primary source of VSC, both in periodontally diseased and healthy individuals. ${ }^{1,6}$, ${ }^{26-28}$ Researchers have been able to find positive correlations between tongue coating status (amount and or presence) and the different parameters directly related with oral malodor. The morphology of the dorsum of the tongue provides additional 
irregularities which serve as retention areas for harbouring bacteria. ${ }^{1,} 29$

Numerous studies have found a relationship between the mechanical removal of tongue coating and the reduction of both organoleptic scores and VSC levels, including reduction in methyl mercaptan levels and the methyl mercaptan/hydrogen sulphide ratio, in both healthy and periodontitis patients, with or without halitosis. Mechanical reduction of malodor and of the intraoral bacterial count may be achieved by disrupting the tongue biofilm, thus decreasing the production of VSCs and other volatile organic compounds. ${ }^{28,30,31}$

Various available instruments can be applied to the tongue, and by gentle pressure the majority of the tongue coating can be scraped off. ${ }^{31}$ Brushing the dorsum of the tongue with toothpaste was more effective than brushing the teeth. The duration of these effects varies from 15 to 100 min and depends on the device used to remove the coating over the tongue.

Other studies found a relationship between tongue cleaning and the reduction of both organoleptic scores and levels of volatile sulphurcontaining compounds. In addition, mechanical cleaning of teeth, such as brushing the teeth and flossing reduced the amount of oral bacteria and substrates, thereby presumably reducing oral malodor. ${ }^{32}$ Interdental cleaning and tooth brushing areessential mechanical means of oral hygiene. This home care removes residual food particles and organisms that cause putrefaction.

Since periodontitis can be a factor in chronic oral malodour. Professional periodontal treatment is mandatory. Thus, initial periodontal therapy in moderate periodontitis patients can be expected to improve breath odour parameters by reducing the number of periodontopathogens. ${ }^{33}$

\section{Chemical approach}

The goal of any antimicrobial treatment would be to reduce the proteolytic, anaerobic flora found on the tongue surface. Treatment procedure should include a debridement component, such as the use of a tongue scraper, possibly in combination with an antimicrobial mouth-rinse. Mouth-rinses with antimicrobial properties can reduce oral malodor by reducing the number of microorganisms chemically.

Often used active ingredients in these products are:

- Chlorhexidine

- Essential oils

- Triclosan

- Cetylpyridinium chloride

- Zinc

- Chlorine dioxide

Combinations of some of the chemicals are also used successfully to reduce malodour. They are:

- Chlorhexidine and zinc

- Cetylpyridinium and zinc ions

- Chlorhexidine, cetylpyridinium chloride and zinc-lactate

All the above chemicals have been proved to reduce malodor effectively.

\section{Conclusion}

The present review described the etiological factors related, methods to assess and the mechanical and chemical therapeutic approaches towards halitosis. Tongue biofilm seems to be directly involved in the production of oral halitosis. It is clear that a successful treatment of halitosis involves an appropriate diagnosis, professional therapy, mechanical plaque control, including tooth brushing and tongue cleaning, possibly combined with the use of an effective antimicrobial mouth rinse.

\section{References}

1. Tonzetich J , Ng SK. Reduction of malodor by oral cleansing procedures. Oral Surg Oral Med Oral Path 1976; 42:172181.

2. Tonzetich J . Production and origin of oral malodor: a review of mechanisms and methods of analysis. J Periodontol 1977; 48:13-20.

3. Yaegaki K, Coil J M. Examination, classification and treatment of halitosis; clinical perspectives. J Can Dent Assoc 2000; 66:257-261. 
4. Miyazaki H, Sakao S, Katoh Y, Takehara T. Correlation between vol atile sulphur compounds and certain oral health measurements in the general population. J Periodontol 1995; 66:679-884.

5. Liu XN, Shinada $K$, Chen $X C$, Zhang $B X$, Yaegaki $K$, Kawaguchi $Y$. Oral malodor-related parameters in the Chinesegeneral population. J Clin Periodontol 2006; 33:3136.

6. Yaegaki K, Sanada K. Volatile sulfur compounds in mouth air from clinically healthy subjects and patients with periodontal disease. J Perio Res 1992; 27:233-888.

7. Yaegaki K, Sanada K. Biochemical and clinical factors influencing oral malodor in periodontal patients. J Periodontol 1992; 63:783-789.

8. Morita M, Wang H-L. Relationship of sulcular sulfide level to severity of periodontal disease and BANA test. J Periodontol 2001; 72:74-78.

9. McNamara TF, Alexander J F, Lee M, Plains M. The role of microorganisms in the production of oral malodor. Oral Surg Oral Med Oral Patho 1972; 34:41-48.

10. Persson S, Claesson R, Carlsson J. The capacity of subgingival microbiotas to produce volatile sulphur compounds in human serum. Oral Microbio I mmunology 1989; 4:169-172.

11. Waler SM. On thetransformation of sulfur-containing amino acids and peptides to volatile sulfur compounds (VSC) in the human mouth. European J Oral Sci 1997; 105:534-537.

12. Kleinberg I, Codipilly M. Modeling of the oral malodour system and methods of analysis. Quintessence International 1999; 30:357-369.

13. Sterer N, Greenstein RB-N, Rosenberg M. â-Galactosidase activity in saliva is associated with oral malodor. J Dent Res 2002; 81:182-185.

14. Sterer N, Rosenberg M. Effect of deglycosylation of salivary glycoproteins on oral malodour production. International Dental J ournal 2002; 52:229-232.

15. Goldberg S, Kozlovsky A, Gordon D, Gelernter I, Sintov A, Rosenberg M. Cadaverine as a putative component of oral malodor. J Dent Res 1994; 73:1168-1172.

16. Amano A, Yoshida Y, Oho T, Koga T. Monitoring ammonia to assess halitosis. Oral Surg Oral Med Oral Path Oral Rad Endo 2002; 94:692-696.

17. Loesche WJ, Kazor C. Microbiology and treatment of halitosis. Periodontology 2002; 28:256-279.

18. Kato H, Yoshida A, Awano S, Ansai T, Takehara T. Quantitative detection of volatile sulphur compound producing microorganisms in oral specimens using realtime PCR. Oral Dis 2005; 11:67-71.

19. Donaldson AC, McKenzie D, Riggio MP, Hodge PJ, Rolph $H$, Flanagan A, et al. Microbiological culture analysis of the tongue anaerobic microflora in subjects with and without halitosis. Oral Dis 2005; 11:61-63.
20. Washio J, Sato T, Koseki T, Takahashi N. Hydrogen sulphide producing bacteria in tongue biofilm and their relationship with oral malodour.J Med Micro 2005; 54:889895.

21. Rosenberg M, Gelernter I, Barki M, Bar-Ness R. Day-long reduction of oral malodor by a two-phase oil:water mouthrinse as compared to chlorhexidine and placebo rinses. J Periodontol 1992; 63:39-43.

22. Greenman J, El-Maaytah M, Duffield J, Spencer P, Rosenberg M, Corry D, et al. Assessing the relationship between concentrations of malodor compounds and odor scores from judges. J Am Dent Asso 2005; 136:749- 757.

23. Rosenberg M, Septon I, Eli I, Bar-Ness R, Gelernter I, Brenner S, et al. Halitosis measurement by an industrial sulphide monitor. J Periodontol 1991; 62: 487-489.

24. Lee PP, Mak WY, Newsome P. The aetiology and treatment of oral halitosis: an update. Hong Kong Med J. 2004; 10(6):414-418

25. Quirynen M, Zhao H, van Steenberghe D. Review of the treatment strategies for oral malodour. Clin Oral Investig 2002; 6(1):1-10

26. Roldan S, Herrera D, O'Connor A, González I, Sanz M. A combined therapeutic approach to manage oral halitosis: a 3- month prospective case series. J Periodontol 2005; 76(6):1025- 1033

27. Farrell S, Baker RA, Somogyi-Mann M, Witt J J, Gerlach RW. Oral malodor reduction by a combination of chemotherapeutical and mechanical treatments. Clin Oral Investig. 2006; 10(2):157-163.

28. Faveri M, Hayacibara MF, Pupio GC, Cury J A, Tsuzuki CO, Hayacibara RM. A cross-over study on the effect of various therapeutic approaches to morning breath odour. J Clin Periodontol 2006; 33(8):555-560.

29. Roldan S, Herrera D, Sanz M. Biofilms and the tongue: therapeutical approaches for the control of halitosis. Clin Oral Investig. 2003; 7:189-197.

30. Krespi YP, Shrime MG, Kacker A. The relationship between oral malodor and volatile sulfur compound-producing bacteria. Otolaryngol Head Neck Surg. 2006; 135(5):671676.

31. Yaegaki K, Coil J M, Kamemizu T, Miyazaki H. Tongue brushing and mouth rinsing as basic treatment measures for halitosis. Int Dent J . 2002; 52(3):192-196.

32. Tanaka M, Anguri H, Nishida N, Ojima M, Nagata $\mathrm{H}$, Shizukuishi S. Reliability of clinical parameters for predicting the outcome of oral malodor treatment. J Dent Res. 2003; 82:518- 522.

33. Greenman J , Duffield J , Spencer P, Rosenberg M, Corry D, Saad S, et al. Study on the organleptic intensity scale for measuring oral malodor. J Dent Res 2004; 83:81-85. 


\section{REFERENCES}

1. National AIDS Control Organization (2003) Prevention of HIV Transmission in health care Settings. In: Training Module on HIV I nfection \& AIDS for Medical Officers 3-16.

2. UNAIDS.Global AIDS response progress reporting 2013. Construction of core indicators for monitoring the 2011 UN Political Declaration on HIV/AIDS. J anuary 2013, Geneva, Switzerland

3. UNAIDS (2013) Report on the Global AIDS epidemic. WHO.

4. Patton LL (2003) HIV disease. Dent Clin North Am 47: 467492.

5. Greenspan D, Greenspan J S, Schiodt M, et al. AIDS and the mouth. Copenhagen: Munksgaard, 1990.

6. Feigal DW, Katz MH, Greenspan D, et al. The prevalence of oral lesions in HIV-infected homosexual and bisexual men: three San Francisco epidemiological cohorts. AIDS 1991;5:519-525.

7. Glick M. Dental management of patients with HIV. Quintessence Publishing Co., Inc., 1994.

8. Scully C, Greenspan J S (2006) Human immunodeficiency virus (HIV) transmission in dentistry. J Dent Res 85: 794800.

9. Patton LL, Phelan J A, Ramos-Gomez FJ , Nittayananta W, Shiboski CH, et al.(2002) Prevalence and classification of HIV-associated oral lesions. Oral Dis 8: 98-109.

10. EC Clearinghouse on Oral Problems Related to HIV Infection and WHO Collaborating Centre on Oral manifestations of the Immunodeficiency Virus. Classification and diagnostic criteria for oral lesions in HIV infection. J Oral Pathol Med 1993;22:289-291.

11. Dodd CL, Greenspan D, Katz MH, et al. Oral candidiasis in HIV infection: pseudomembranous and erythematous candidiasis show similar rates of progression to AIDS. AIDS 1991;5:1339-1343.

12. Fung J C, Shanley J, Tilton RC. Comparison of the detection of herpes simplex virus in direct clinical specimens with herpes simplex virus-specific DNA probes and monoclonal antibodies. J Clin Microbiol 1985;22:748-753.

13. MacPhail LA, Greenspan D, Schiodt M, et al. Acyclovirresistant, foscarnet-sensitive oral herpes simplex type 2 lesion in a patient with AIDS. Oral Surg Oral Med Oral Pathol 1989;67:427-432.

14. Quinnan GV J r, Masur H, Rook AH, et al. Herpes virus infections in the acquired immunodeficiency syndrome. J AMA 1984;252:72-77.

15. Greenspan D, de Villiers EM, Greenspan J S, et al. Unusual HPV types in oral warts in association with HIV infection. J Oral Pathol 1988;17:482-488.

16. J ones AC, Freedman PD, Phelan J A, et al. Cytomegalovirus infections of the oral cavity: a report of six cases and review of the literature. Oral Surg Oral Med Oral Pathol 1993; 75:76-85.

17. Greenspan D, Greenspan J S, Hearst NG, et al. Relation of hairy leukoplakia to infection with the human immunodeficiency virus and the risk of developing AIDS. J Infect Dis 1987;155: 475-481.
18. Greenspan J S, Mastrucci MT, Leggott PJ, et al. Hairy leukoplakia in a child. AIDS 1988;2:143.

19. Winkler J R, Herrera C, Westenhouse J, et al. Periodontal disease in HIV-infected and uninfected homosexual and bisexual men. AIDS 1992;6:1041-1043.

20. Glick $M$ et al. Necrotizing ulcerative periodontitis: a marker for immune deterioration and a predictor for the diagnosis of AIDS. J Periodontol 1994; 65:393-397.

21. Robinson P. Periodontal diseases and HIV infection. A review of the literature. J Clin Periodontol 1992; 19:60914.

22. Winkler J R, Murray PA. Periodontal disease: a potential intraoral expression of AIDS may be rapidly progressive periodontitis. CDA J 1987;15:20-24.

23. Rams TE, Andriolo M J r, Feik D, et al. Microbiological study of HIV-related periodontitis. J Periodontol 1991;62:74-81.

24. Murray PA, Holt S. Microbiology of HIV-associated gingivitis and periodontitis. In: Robertson PB, Greenspan J S, eds. Oral manifestations of AIDS. Littleton, Mass.: PSG Publishing, 1988

25. Volpe F, Schwimmer A, Barr C. Oral manifestations of disseminated Mycobacterium avium intracellulare in a patient with AIDS. Oral Surg Oral Med Oral Pathol 1985;60:567-570.

26. Centers for Disease Control and Prevention. 1993 sexually transmitted diseases treatment guidelines. MMWR Morb Mortal Wkly Rep 1993 Sep 24; 42(RR-14):1-102.

27. Manjari M, Popli R, Paul S, Gupta VP, Kaholon SK. Prevalence of oral cavity, pharynx, larynx and nasal cavity malignancies in Amritsar, Punjab. Indian J Otolaryngol Head Neck Surg 1999;48:191-195.

28. Epstein J B, Cabay RJ , Glick M. Oral malignancies in HIV disease: changes in disease presentation, increasing understanding of molecular pathogenesis, and current management. Oral Surg Oral Med Oral Pathol Oral Radiol Endod 2005; 100(5):571-578.

29. Marcusen DC, Sooy CD. Otolaryngol ogic and head and neck manifestations of acquired immunodeficiency syndrome (AIDS). Laryngoscope 1985;95:401-405.

30. Moore RD, Kessler H, Richman DD, et al. Non-Hodgkin's lymphoma in patients with advanced HIV infection treated with zidovudine. J AMA 1991;265:2208-2211.

31. MacPhail LA, Greenspan D, Feigal DW, et al. Recurrent aphthous ulcers in association with HIV infection: description of ulcer types and analysis of T-cell subsets. Oral Surg Oral Med Oral Pathol 1991; 71:678-683.

32. Schiodt M, Dodd CL, Greenspan D, et al. Natural history of HIV-associated salivary gland disease. Oral Surg Oral Med Oral Pathol 1992; 74:326-331.

33. Soberman N, Leonidas J C, Berdon WE, et al. Parotid enlargement in children seropositive for human immunodeficiency virus: imaging findings. AJ R 1991;157:553-556.

34. Schiodt M, Greenspan D, Daniels TE, et al. Parotid gland enlargement and xerostomia associated with labial sialadenitis in HIV-infected patients. J Autoimmun 1989;2:415-425. 